\title{
Optical limiting studies and saturated output of continuous wave laser in Fluorescein solution
}

\author{
Aqeel Lafta Mghames, Hussain Ali Badran, Hussain Falih Hussain
}

\begin{abstract}
Optical limiting performances in Fluorescein with different concentration of $2,4,6$ and $8 \mathrm{mM}$ are investigated by using $473 \mathrm{~nm}$ continuous wave (cw) laser. The optical limiting behavior is investigated via transmission measurement through the sample at different concentrations. The investigation shows that the optical limiting capability is concentration dependent. The results showed that the sample has obvious optical limiting effect. $8 \mathrm{mM}$ concentration has the best limiting effect among the four concentrations chosen. It is also found that the threshold value of optical limiting is affected by sample absorption coefficient. The Fluorescein exhibits good optical limiting properties in solution.
\end{abstract}

Index Terms - Optical limiting, Laser, Fluorescein, limiting thresholds

\section{INTRODUCTION}

Organic molecules with large third-order optical nonlinearities continue attracting attentions because of their potential application in optical communications, optical storage, optical computing, harmonic generation, all optical switching, optical limiting, eye and sensor protection, etc. $[1,2]$. Among all the nonlinear optical (NLO) properties applications, optical limiting (OL) is one of the most promising in practice, such as the protection of human eyes and optical sensors $[3,4]$. Several mechanisms could lead to optical limiting behaviour, such as reverse saturable absorption (RSA), two-photon absorption (TPA), nonlinear refraction and optically induced scattering [5,6]. In RSA, the absorption coefficient increases with increasing light intensity. Optical limiters based on RSA are very transparent for weak light and get opaque for the intense light.

Investigations of optical limiting performance have attracted considerable attention because of the increasing demands in laser protection against laser threats to sensors and human eyes. One major approach to laser protection is through the use of optical limiters. The present challenge is to develop new nonlinear optical materials with stronger optical limiting properties [7-9]. Typical optical limiting

materials include carbon black suspension [10,11], carbon nanotube [12-15], azo dye [16-19], metallophthalocyanines [20] and metal clusters [21,22].

Recently, because of the rapid progress in synthetic chemistry, various metal nanoparticles and material [23-34] have been considered as potential optical limiting materials.

Here we report on the experimental investigation of the optical limiting properties of an organic compound, namely Fluorescein has been experimentally investigated by using

Aqeel Lafta Mghames, Department of Physics, University of Basrah, College of Sciences, Basrah, Iraq.

Hussain Ali Badran, Department of Physics, University of Basrah, College of Education for pure Sciences, Basrah,Iraq.

Hussain Falih Hussain, Department of Physics, University of Basrah, College of Education for pure Sciences, Basrah, Iraq continuous wave solid state laser SDL as excitation source at $473 \mathrm{~nm}$ wavelength. The organic compound which is used in this study are considered to be promising materials, mainly because they offer many advantages such as high damage threshold, easy molecular design, architectural flexibility, low cost and good process ability to form optical devices. Moreover, this organic compound has good solubility in chloroform.

\section{EXPERIMENT}

\section{A. Preparation of Sample}

Fluorescein, with molecular formula $=\mathrm{C}_{20} \mathrm{H}_{12} \mathrm{O}_{5}$ and molecular weight $=332.31 \mathrm{gmmol}^{-1}$, has been selected for our experiments. The chemical structure of Fluorescein is shown in Fig. 1. The solution sample of the Fluorescein was prepared as follows: $0.5 \mathrm{~g}$ of the sample powder was dissolved in $10 \mathrm{ml}$ of chloroform, the organic solution was stirred at room temperature for $30 \mathrm{~min}$ and then the solution was filtered through a $0.2 \mathrm{~mm}$ syringe filter.<smiles>O=C1OC2(c3ccc(O)cc3Oc3cc(O)ccc32)c2ccccc21</smiles>

Figure 1 Chemical structure of Fluorescein.

\section{B. $U V$-Visible spectroscopic studies}

The linear UV-Vis (Ultraviolet-visible) absorption spectra for the Fluorescein in solvent chloroform was recorded using Cecil Reflected- Scan CE 3055 reflectance spectrometer. The optical absorption for the Fluorescein in the solvent chloroform with different concentrations, 2, 4, 6 and $8 \mathrm{mM}$, respictivily, shows absorption peak at $461 \mathrm{~nm}$ as can be seen in Fig. 2. Also it can be seen from the Fig. 2 that the absorbance of the sample increases with increasing the concentration due to the increase in the number of molecules per unit volume, so the absorbance will be increased.

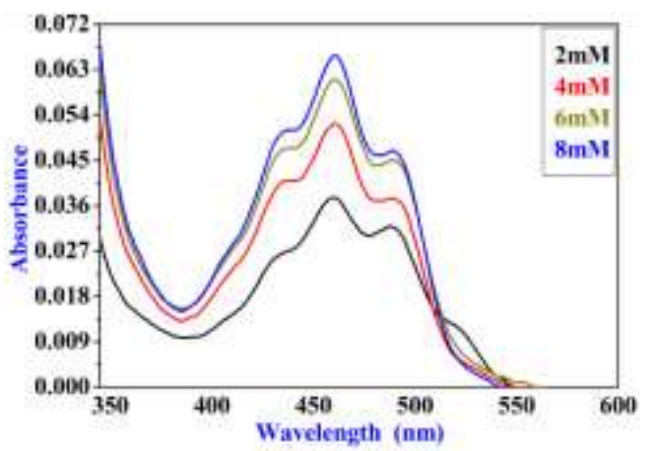

Figure 2 Linear absorption spectra of Fluorescein solution with different concentrations. 


\section{The absorption coefficient}

The spectrum of the optical absorption was computed from the absorbance data. The absorption coefficient $(\alpha)$ has been obtained directly from the absorbance against wavelength curves using the relation [35-38]

$\alpha=2.303 \mathrm{~A} / \mathrm{L}$

where $\mathrm{L}$ is the sample thickness and $\mathrm{A}$ is the absorbance. The values of absorption coefficient $(\alpha)$ at wavelength 473 $\mathrm{nm}$ for Fluorescein solution with different concentrations have been calculated using Eq. 1 and they are given in Table 1 .

\section{OPTICAL LIMITING TECHNIQUE}

The experimental set-up for the demonstration of an optical limiting effect is shown in Ref [39] where the observation screen is replaced by an aperture that is centered at the optical axis. A cw solid state laser (SDL) was used as a light source. The wavelength of the laser can be tuned among $473 \mathrm{~nm}$. The laser beam was focused normally into the sample by a positive lens with a focal length of $+5 \mathrm{~cm}$. In the case of the sample solution, a $1 \mathrm{~mm}$ quartz cell was used to contain the solution of Fluorescein in the solvent chlorophorm. The sample could be moved back and forth along the direction of the optical axis in order to change the position of the focal point of the lens with respect to the sample. An aperture A of variable diameter is used to control the cross-section of the beam coming out of the sample. This beam is then made to fall on the photo detector (PD). The input laser intensity is varied systematically and the corresponding output intensity values are measured by the photo detector that is connected to a power meter (Field Max II-To+OP-2 Vis Sensor). Fluorescein solution with different concentrations is placed at the valley behind the focal point. The input power of the laser beam and the corresponding output power through the aperture are detected by a photodetector fed to the digital power meter. So, the characteristic curve of the output power as a function of the input power can be obtained.

The dependence of optical limiting on the sample concentration is studied for different sample concentrations by using the configuration shown in Ref [39]. In this experiment the sample was placed behind the focal point of the lens and the aperture size was set to be $5 \mathrm{~mm}$ in diameter. The optical limiting curve for the sample solution at different concentrations is shown in Fig. 3. The output power rises initially with an increase in input power for all the samples, but after a certain threshold value the sample starts defocusing the beam, resulting in a greater part of the beam cross-section to be cut off by the aperture [40].

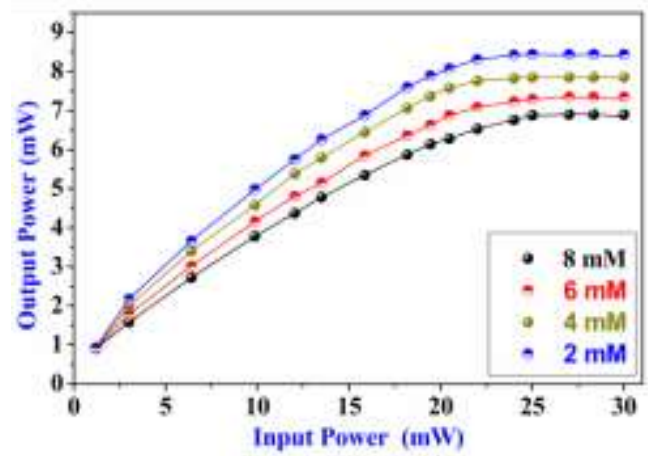

Figure 3 Optical limiting curves
Thus the transmittance recorded by the photo-detector remains reasonably constant showing a plateau region and is saturated at a point defined as the limiting amplitude. i.e., the maximum output intensity, showing obvious limiting property. The saturated output value at which limiting occurs for the sample solution is shown in Fig. 4 for different concentrations. It can be seen from Fig. 4 that the saturated output value decreases with an increasing concentration.

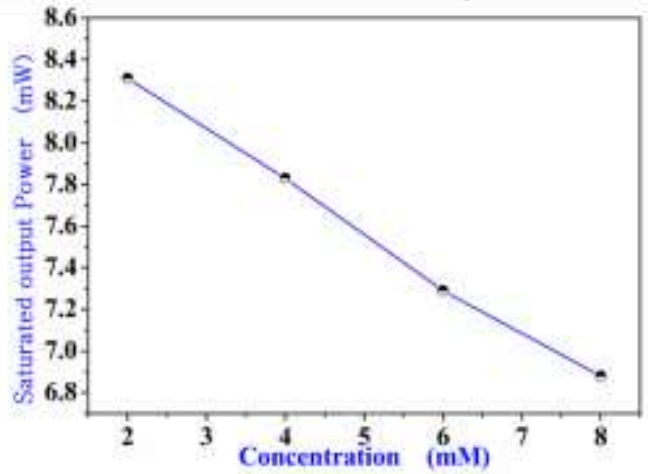

Figure 4 Concentration dependence of saturated output power.

Fig. 5 shows the normalized transmission curves as a function of incident input power for 2, 4, 6 and $8 \mathrm{mM}$ concentrations of Fluorescein. The optical limiting abilities are quantitatively different. The optical limiting thresholds (defined as the incident input power where the transmission reduces by $50 \%$ )are measured and they are given in Table 1 .

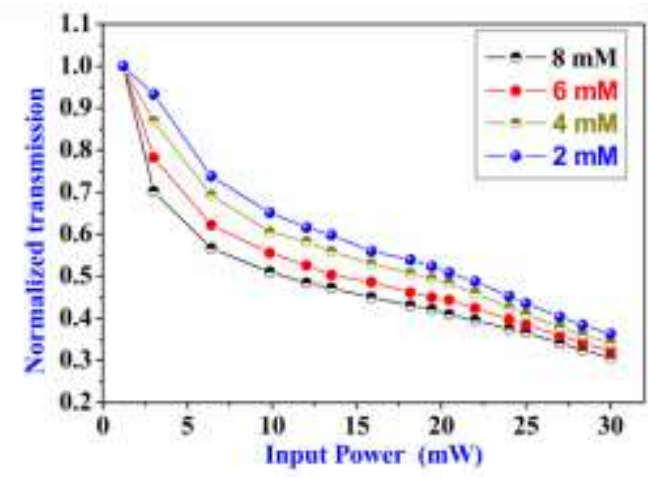

Figure 5 Normalized transmission curves of optical limiting.

It is well known that concentration plays very important role in the optical limiting action. The optical limiting effect is enhanced and the transmittance decreases with increasing concentration. This is because a sample with high concentration has more molecules per unit volume participating in the interaction during the nonlinear absorption processes. So the optical limiting responses of the low concentration sample are generally much weaker than those of high concentrated samples, while high concentrated samples exhibits strong optical limiting with the range of this study. However, the concentration of the sample should be chosen carefully in order to reach the concentration threshold, which is an important factor in the investigation of optical limiting $[41,42]$. The limiting behavior observed in all samples is attributed mainly to nonlinear refraction. Since the samples were pumped with cw laser beam the arising nonlinearities are predominantly thermal in nature $[43,44]$. Due to change in refractive index of the material selffocusing and self-defocusing can be observed in the material, leading to reduction of transmittance at far field 
(due to distortion of spatial profile of Gaussian beam). Reduced transmittance in the far field gives better optical limiting performance.

Table 1 Optical parameters and limiting thresholds of Fluorescein.

\begin{tabular}{|c|c|c|c|}
\hline $\begin{array}{c}\text { Concentration } \\
(\mathrm{mM})\end{array}$ & Absorbance & $\begin{array}{c}\text { absorption } \\
\text { coefficient } \\
\left(\mathrm{cm}^{-1}\right)\end{array}$ & $\begin{array}{c}\text { Limiting } \\
\text { threshold } \\
(\mathrm{mW})\end{array}$ \\
\hline 2 & 0.031 & 0.713 & 21.1 \\
\hline 4 & 0.041 & 0.944 & 18.8 \\
\hline 6 & 0.049 & 1.128 & 13.8 \\
\hline 8 & 0.051 & 1.174 & 10.8 \\
\hline
\end{tabular}

\section{CONCLUSION}

The optical limiting performances of Fluorescein solution have been investigated at 2, 4, 6 and $8 \mathrm{mM}$ concentrations, using $\mathrm{cw}$ laser beam at $473 \mathrm{~nm}$ wavelength. The results show that the optical limiting efficiency is concentration dependent. Excellent optical limiting performances with relatively good stability for Fluorescein solution have been observed until the incident input power approaches $30 \mathrm{~mW}$ without sample damaging. It is also found that the threshold value of optical limiting is affected by sample concentration. The experimental results show that the optical limiting threshold and saturated values of Fluorescein solution with 8 $\mathrm{mM}$ concentration are much lower than those of other films with 2, 4, and $6 \mathrm{mM}$ concentrations. These materials can find potential applications in various optical limiting devices. The sample which is used in this study are considered to be promising materials, mainly because they offer many advantages such as available, architectural flexibility, high damage threshold, easy molecular design, low cost and good process ability to form optical devices. Moreover, this organic compound show good optical limiting properties.

\section{REFERENCES}

[1] H. A. Badran, Z-Scan Measurement For The Thermo-Optic Coefficient and Transmitted Beam Profile of 1.8-Dihydroxy-Naphthalin-3, 6 Disulfonic Acid-[2-(4-azo)]-N-(5-Methyl-3- Isoxazolyl) -Benzene Sulfonamide, Advances in Physics Theories and Applications, vol.26, pp.36-44, 2013.

[2] H. A. Badran, A. A. Al-Fregi, R. K. Fakher Alfahed, A. S. Al-Asadi,"Study of thermal lens technique and third-order nonlinear susceptibility of PMMA base containing 5',5" dibromo-o cresolsulfophthalein," J Mater Sci: Mater Electron, vol.28 , no.22, pp.17288-17296, 2017.

[3] H. A. Badran and K. etamm Abd AL-Adel, "Optical Nonlinear Properties and Optical Limiting Effect of Congo red dye under CW Laser, Misan Journal for Academic Studies, Vol. 11, no. 21, pp.1-9, 2012.

[4] H. A. Badran and N. Al-huda S.Yakop,"Study of the optical limiting properties of Ethidium Bromide under CW laser illumination,"Inter. $J$. of Engineering Research and Management (IJERM), vol.1, no.8, pp.67-69, 2014.

[5] H. A. Badran and A. A. Al-Fregi, "Synthesis and Study of Nonlinear Optical Properties of a New Azo Dye by Z-Scan Technique, International Journal of Semiconductor Science \& Technology (IJSST) vol.2, no.1, pp.26-36, 2012.

[6] H. A. Badran, H.A.Sultan and Q.M. Ali, “ Surface morphology and thermal figure of merit of a new compound thin film," J Mater Sci: Mater Electron. vol.27, no.7, pp. 6735-6744, 2016.

[7] M. Sh. Hussain, Q. M. A. Hassan, Hussain A. Badran and C. A. Emshary, "Synthesis, Characterization And Third-Order Nonlinear Optical Properties Of Schiff Base Dimer, International Journal of
Industrial Engineering \& Technology (IJIET) vol. 3, no. 4, 57-64, 2013.

[8] Samson.A. Jenekhe, S.K. Lo and S.R. Flom, “ Third- order nonlinear optical properties of a soluble conjugated polythiophene derivative, Appl. Phys. Lett. vol.54, no. 25, p. 2524, 1989.

[9] H. S. Shaaker, W. A. Hussain and H. A. Badran, "Determination of the optical constants and optical limiting of doped malachite green thin films by the spray method, Advances in Applied Science Research, vol.3, no.5,pp: 2940-2946, 2012.

[10] K. Mansour, M. J. Soileau and E.W. Van Stryland, "Nonlinear optical properties of carbon- black suspensions (ink), J. Opt. Soc. Am. B 9, no.7, pp.1100-1109, 1992.

[11] K. M. Nashold and D. Powell Walter, "Investigations of optical limiting mechanisms in carbon particle suspensions and fullerene solutions, J. Opt. Soc. Am. B 12, no.7, pp.1228-1237, 1995.

[12] X. L. Zhang, Z. B. Liu, X. Zhao, X. Q. Yan, X. C. Li, and J. G. Tian, "Optical limiting effect and ultrafast saturable absorption in a solid PMMA composite containing porphyrin-covalently functionalized multi-walled carbon nanotubes, Optics Express vol.21, no.21, pp.25277- 25283, 2013

[13] L. Vivien, E. Anglaret, D. Riehl, F. Bacou, C. Journet, C. Goze, M. Andrieux, M. Brunet, F. Lafonta, P. Bernier and F. Hache, "Single-wall carbon nanotubes for optical limiting. Chem. Phys. Lett. vol.307, no.5-6, pp.317-319, 1999.

[14] L. Vivien, E. Anglaret, D. Riehl, F.Hache, F. Bacou, M. Andrieux, F. Lafonta, C.Journet, C.Goze, M. Brunet and P. Bernier,"Optical limiting properties of single wall carbon nanotubes, Optics Communications, vol.174, no.1-4, pp.271-275, 2000.

[15] Z. Xia Jin, L. Huang, S.H. Goh, G.Q. Xu and W. Ji, "Size dependent optical limiting behavior of multi-walled carbon nanotubes, Chem. Phys. Lett. vol.352, no.5-6, pp. 328-333, 2002.

[16] A. Y.Al-Ahmad, Q. M. Ali Hassan, H. A. Badran and K. A. Hussain, "Investigating some linear and nonlinear optical properties of the azo dye (1-amino-2-hydroxy naphthalin sulfonic acid-[3-(4-azo)]-4-amino diphenyl sulfone), Optics \& Laser Technology, vol.44 pp.1450-1455, 2012.

[17] H. A. Badran. "Investigation of the Nonlinear Optical Response of 3(Dimethylamino)-7- Aminophenothiazin-5-Ium Chloride Dye, IOSR Journal of Applied Physics (IOSRJAP), vol.1, no.5, pp. 33-37, 2012.

[18] K. Abd AL-Adel and H. A. Badran, " $\chi^{3}$ measurements and optical limiting in Bismarck Brown Ydye, International Journal of Emerging Technologies in Computational and Applied Sciences (IJETCAS) vol.8, no.1, pp. 64-68, 2014.

[19] K. Abd AL-Adel and H. A. Badran," Nonlinear optical properties and diffraction ring patterns of benzo congo red," European J. of Applied Engineering and Scientific Research, vol.1, no.2, pp.66-72, 2012.

[20] H. A. Sultan, H. A. Badran, A. Y. Al-Ahmad and C. A. Emshary,“ Experimental and Theoretical Study of the Laser Induced Diffraction Pattern in the Acid Orange 10 Dye: Polyacrylamide Gel,"J. of Basrah Researches (Sciences) A, vol.39, no.2, pp.1-12, 2013

[21] W. Ji, S. Shi, H.J. Du, P. Ge, S.H. Tang and X.Q. Xin, "Optical Power Limiting with Solutions of Hexagonal Prism Cage Shaped Transition-Metal Cluster Mo2Ag4S8(PPh3)4, J. Phys. Chem. Vol.99, no.48, pp.17297-17301, 1995.

[22] T. Xia, A. Dogariu, D. J. Hagan, A.A. Said, E.W. Stryland and S. Shi, "Nonlinear response and optical limiting in inorganic metal cluster $\mathrm{Mo}_{2} \mathrm{Ag}_{4} \mathrm{~S}_{8}\left(\mathrm{PPh}_{3}\right)_{4}$ solutions, J. Opt. Soc. Am. B, vol.15, no.5 pp.1497-150, 1998.

[23] H. A. Badran, K. Abd. AL-Aladil, H. G. Lazim and A. Y. Al-Ahmad, "Thermal blooming and photoluminescence characterizations of sol-gel CdO- $\mathrm{SiO}_{2}$ with different nanocomposite, J Mater Sci: Mater Electron, vol.27, pp.2212-2220, 2016.

[24] H. A. Badran, K. I. Ajeel and H. G. Lazim, "Effect of nano particle sizes on the third-order optical non-linearities and nanostructure of copolymer P3HT:PCBM thin film for organic photovoltaics, Materials Research Bulletin, vol.76,pp.422-430, 2016.

[25] H. A. Badran, "Thermal lens and all optical switching of new organometallic compound doped polyacrylamide gel, Results in Physics, vol.4, pp.69-72, 2014

[26] H. A. Badran, H. F. Hussain and K. I. Ajeel, "Nonlinear characterization of conducting polymer and electrical study for application as solar cells and its antibacterial activity, Optik, vol.127 pp.5301-5309, 2016.

[27] H. A. Badran, A. Y. Al-Ahmad, Q. M. Ali and C. A Emshary, "Determination of optical constants and nonlinear optical coefficients of Violet 1-doped polyvinyl alcohol thin film, Pramana J. phys. vol.86, pp.135-145, 2016. 
[28] H. A. Badran, A.Y.AL-Ahmad, M. F.AL-Mudhaffer and C. A.Emshary, "Nonlinear optical responses and limiting behavior of sulfadiazine-chromotropic acid azo dye, Opt Quant Electron, vol.47,pp. 1859-1867, 2015.

[29] H. A. Badran, "Thermal properties of a new dye compound measured by thermal lens effect and Z-scan technique, Appl. Phys. B vol.119, pp.319-326, 2015.

[30] N. Al-Had S.Yakop and H. A. Badran,“ Single-Beam Z-Scan Measurement of the Third-Order Optical Nonlinearities of Ethidium BromideInt,"Journal of Engineering Research an Applications, vol.4, no.3, pp.727-731, 2014.

[31] Lakshminarayana Polavarapu, Q. H. Xu, M. S. Dhoni and W. Ji, "Optical limiting properties of silver nanoprisms, Appl. Phys Lett. vol.92, p. 263110, 2008

[32] Ya chen Gao, Yu xiao Wang, Ying lin Song, Yu liang Li, S.L. Qu, H. B. Liu and J. feng Zu, "Strong optical limiting property of a novel silver nanoparticle containing $\mathrm{C}_{60}$ derivative. Opt. Commun. vol. 223 no.1-3, pp.103-108, 2003.

[33] Lionel François, Mehran Mostafavi, Jacqueline Belloni and Jacques A. Delaire, "Optical limitation induced by gold clusters: Mechanism and efficiency, Phys. Chem. Chem. Phys. vol.3,no.22, pp.4965- 4964, 2001.

[34] Y. Gao, Y. Song, Y. Li, Y. Wang, H. Liu and D. Zhu, "Large optical limiting of [60] fullerene-substituted terpyridine palladium nanoparticles, Appl. Phys. B. vol.76, no.7, pp.761-763, 2003.

[35] H. A. Badran, A.Y. Taha, A. F.Abdulkader and C. A.Emshary, "preparation and study of the electrical and optical properties of a new azo dye (4-acetaminophenol-[2-(4-azo)]-4- amino dipheyl sulfone) $J$. Ovonic Res.,vol. 8, pp.161-170, 2012

[36] H. A. Badran, "study on optical constants and refractive index dispersion of neutral red doped polymer film, American J. of Applied Sciences, vol.9, pp.250-253, 2012.

[37] H. G. Lazim, K. I. Ajeel and H. A. Badran, "The photovoltaic efficiency of the fabrication of copolymer P3HT: PCBM on different thickness nano-anatase titania as solar cell, Spectrochimica Acta Part A: Molecular and Biomolecular Spectroscopy,vol.145, pp.598-603, 2015.

[38] H.A. Badran, M. F.Al-Mudhaffer, Q. M. Hassan and A.Y. Al-Ahmad, "study of the linear optical properties and surface energy loss of 5',5"-dibromo-o-cresolsulfophthalein thin films, Chalcogenide Lett. vol.9, pp.483-493, 2012.

[39] H. A. Badran, Riyadh Ch. Abul-Hail, Hussain S. Shaker, Abdulameer I. musa and Qusay M. A. Hassan, "An all-optical switch and third-order optical nonlinearity of 3,4-pyridinediamine, Appl. Phys. B vol.123,p.31, 2017

[40] A. Imran, Q. M. Ali Hassan and H. A. Badran, "Third-Order Nonlinear Optical Response and Optical Limiting Behavior of 3,4-Diaminopyridine, European Scientific Journal vol.10, no.9, pp.382-390, 2014

[41] H. A. Badran, Q. M. Ali Hassan and A. Imran, " Large third order optical nonlinearity and optical limiting properties of a 3,4-diaminopyridine, $J$ Mater Sci: Mater Electron vol.26, pp:5958-5963, 2015 .

[42] H. A. Badran, A. Imran and Q. M. A Hassan, "Thermal diffusivity of 2,3-Pyridinediamine determination by thermal blooming, Optik, vol. 127,pp.2659-2665, 2016.

[43] H. A. Badran, Q. M. A. Hassan and A. Imran, "A Quantitative Study of the Laser-Induced Ring Pattern and optical limiting From 4-Chloro-3-methoxynitrobenzene solution, Journal of Basrah Researches (Sciences) A, vol. 41, no.2, pp.51-57, 2015.

[44] R. Ch. Abul-Hail, "Optical limiting behavior correlated with the surface and etching time of irradiated nuclear track detector, J Mater Sci: Mater Electron, vol.28, pp.2311-2316, 2017.

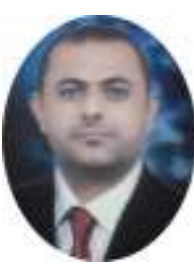

Aqeel Lafta Mghames born in Basrah, received his BSc degree in physics in 2001 from the University of Basra, Iraq. He is currently with the Physics Laboratory of linear and nonlinear optics properties, Department of Physics,University of Basrah, College of Education for pure Sciences, Basrah, Iraq, doing research toward a M.Sc degree. His research interests include waveguide laser, thin film, self diffraction and optical limiting.

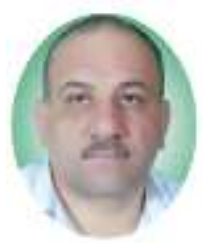

Hussain Ali Badran received his $\mathrm{PhD}$ degree in physical electronics in the Department of Electronic Science and Technology, Harbin Institute of Technology (HIT), Harbin, China, in 2004. At present, he is a professor at University of Basrah, Education College for pure sciences and has been engaged in research in the fields of laser technology, laser spectroscopy, and nonlinear optics. He has published more than 110 papers.

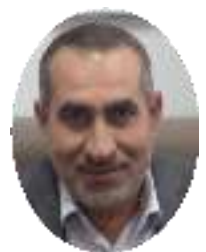

Hussain F. Hussain received his M.Sc degree in physics in 2000 and $\mathrm{PhD}$ degree in Polymer Physics in 2011 from the University of Basra, Iraq. $\mathrm{He}$ is a professor at University of Basrah, Education College for pure sciences. He spent more than five years in the Polymer solar cell laboratory in the physics department at Basra. He has published more than 40 papers. 